Citation: MALIK, S, BLAKE, H and BATT, M., 2011. How Healthy Are Our Nurses? New and registered nurses compared. British Journal of Nursing. 20(8), 489-96.

\title{
How healthy are our nurses? New and registered nurses compared
}

Sumaira Malik ${ }^{1}$, Holly Blake ${ }^{1}$, Mark Batt ${ }^{2}$

${ }^{1}$ University of Nottingham, Nottingham, UK.

${ }^{2}$ Nottingham University Hospitals NHS Trust, UK.

\section{Abstract}

This study examined the health behaviour of nursing staff, comparing registered and pre-registered nurses in terms of their self-reported health and lifestyle behaviour. In total, 325 pre-registered nurses and 551 registered nurses, based at the same university teaching hospital and located within an acute NHS trust, completed a self-administered health and lifestyle questionnaire survey. With the exception of smoking behaviour, registered nurses generally had a healthier lifestyle compared with pre-registered nurses. However, when examining the overall health profile of the sample, the study reveals that there is room for improvement in the health and lifestyle behaviour exhibited by both registered and pre-registered nurses. Almost half of the sample failed to meet public health recommendations for levels of physical activity, almost two-thirds did not consume five portions of fruit or vegetables daily and almost half ate foods that were high in fat and sugar content on a daily basis. These findings are alarming given the current government emphasis on the health of NHS staff and the important role that nurses play in influencing lifestyle choices among their patients. There is an urgent need to target education and support services to improve the diet and exercise habits of nursing professionals. 
Key words: Nurses; Health behaviour; Physical activity; General health; Smoking; Diet; Role models; Education

\section{Background}

Nursing staff play an integral role in promoting healthy lifestyle behaviour to patients (Connolly et al, 1997). As nurses typically have the highest frequency of direct contact with patients, they therefore serve as an important point of reference for positive health habits that may be imitated by their patients (Aristizabal and Rodriguez, 1998). Recent UK government publications emphasize that because frontline NHS staff, particularly nurses, are uniquely placed to advise patients about health and lifestyle issues, they can function as important role models in the promotion of government messages concerning healthy lifestyle choices (Department of Health (DH), 2004a,b; 2008a,b; 2009a,b). Ensuring NHS nurses take responsibility for their own health and act as good role models for healthy living is thus considered imperative for the successful delivery of government health policy, both within the UK and internationally (DH, 2009a; Prime Minister's Commission on the Future of Nursing and Midwifery in England, 2010). However, despite nurses' healthpromoting role and professional knowledge concerning healthy lifestyle choices, research indicates that many nurses do not transfer this knowledge to their own health and lifestyle behaviour. Studies of registered and pre-registered nurses reveal that nursing professionals across a number of different countries tend to exhibit higher rates of smoking than both the general population and other health professionals, with some studies showing that as many as $45-57 \%$ of nurses are current smokers (Andrea et al, 2001; Chalmers et al, 2002; Ruiz and 
Bayle, 2003; Hodgetts et al, 2004; Pappas et al, 2005; Vagropoulos et al, 2006; Watson et al, 2006; Alberdi-Erice et al, 2007; Kumbrija et al, 2007; Sezer et al, 2007; Smith and Leggat, 2007; Kutlu, 2008). Furthermore, Hodgetts et al (2004) found that of the current smokers in their sample of health professionals, nurses were significantly less likely to be considering to quit smoking when compared with other health professionals.

One factor that may impact on the prevalence of smoking among nurses is the occurrence of work-related stress (Hope et al, 1998). Nursing is seen as an inherently stressful occupation, with high levels of burnout, staff turnover and sickness absence (Kirklady and Martin, 2000; Sharma et al, 2007; Watson et al, 2009). Nurses are exposed to several work-related stressors, including the experience of death, the emotional demands of patients and their families, shift work, long working hours, budget cuts and a continuously changing work environment (Hillhouse and Adler, 1997). These stressors may account for the higher prevalence of smoking in the nursing profession when compared with other health professionals (McVicar, 2003).

Work-related stressors may also influence the ability of nurses to engage in regular exercise and maintain positive dietary habits. Indeed, research has shown that levels of physical activity among nurses is low, with many nurses failing to meet the UK government's recommended minimum of 30 minutes exercise five times a week (Surawongsin, 2002; Jinks et al, 2003; Nursing Times, 2008; Zapka et al, 2009). Additionally, research has shown that nurses regularly consume foods that are high in fat and sugar content (Cheung, 2003; Zapka et al, 2009), which has been associated with time pressures (Nursing Times, 2008) and shift-work patterns (Wong et al, 2010) in the nursing occupation. 
These findings have several important implications for the role of nurses as health promoters. First, it has been suggested that there may be a link between nurses' health practices and their tendency to raise lifestyle issues with patients (McDowell et al, 1997; Rush et al, 2005). For example, McDowell et al (1997) found that nurses who engaged in regular exercise were more likely to promote physical activity among patients than nurses who were physically inactive. Similarly, studies have shown that nurses who are smokers themselves are less willing to promote healthy behaviour among patients who smoke than nurses who are not current smokers (McKenna et al 2001; Chalmers et al, 2002; Lenz, 2008; Radsma and Bottorff, 2009). Second, poor weight management practices can lead to high levels of obesity, with recent figures revealing that around 700 000 of the 1.2 million NHS staff are thought to be overweight or obese (DH, 2009b). Hicks et al (2008) argue that members of the public are likely to have significantly more confidence in the ability of normal-weight nurses to provide education about diet and exercise when compared with overweight nurses. Thus, poor health and lifestyle behaviour exhibited by nurses may impact on the credibility of their health-promotion messages.

Finally, poorer health behaviour will inevitably lead to poorer physical and mental health, which has been linked to high levels of fatigue, stress and burnout, and in turn a high level of sickness absence in the nursing profession (Kirklady and Martin, 2000; Blaber, 2005; McElligott et al, 2009). This is critical because absence in the workplace as a result of sickness has been identified in the 2010 UK Budget as a target for cutting costs in the UK economy. Also, on an international level, sickness absence among nursing staff has significant implications for the quality of care given to patients, with lower staffing levels 
resulting in less one-to-one time with patients and poorer work performance (Thompson, 2007; McElligott et al, 2009). Consequently, improving the health and lifestyle practices of nurses is both in line with UK government strategy for reducing sickness absence and presents an important first step in promoting positive lifestyle choices to the general population, thus supporting the continuing national and international drive to improve population health $(\mathrm{DH}$, 2009a).

\section{Aims of this study}

To identify the extent to which the current (registered nurses) and future (preregistered nurses) health promoters of the NHS are transferring their knowledge of healthy lifestyle choices to their own behaviour, and to identify key areas for intervention, this study examined and compared the self-reported health and lifestyle behaviour of registered and pre-registered nurses.

\section{Method}

A cross-sectional comparative design was used based upon secondary analysis of two existing datasets. Data were collected from registered nurses as part of a baseline survey for a large cohort study evaluating a workplace wellness intervention at a university teaching hospital based at an NHS trust (Lee et al, 2008). Data were also collected from pre-registered nursing students as part of a cross-sectional survey conducted at the same NHS trust. Ethical approval was gained from the Centre of Research Ethical Campaign (COREC), local NHS research and development (staff survey) and the local university's Medical School Ethics Committee (student survey); data were collected in 2007-8. Completion was voluntary and anonymous. Nurses were asked to return their questionnaires via the internal mail system within a four-week period, followed 
by an electronic email reminder, which has been shown to improve response rates in questionnaire surveys (Braithwaite et al, 2003). Return of the form was taken to be informed consent. Data were entered into SPSS for Windows 16.0 and a $10 \%$ data check and descriptive analysis were conducted.

The questionnaire included items on demographic characteristics, physical activity levels, barriers to physical activity, general health, smoking and diet.

\section{Demographic characteristics}

Participants were asked to provide their age, gender, height and weight (from which body mass index (BMI) was calculated).

\section{Physical activity}

Participants were asked to specify whether or not they were currently physically active: 'Think about all the physical activity you do in a typical week. Do you take part in physical activity or exercise on most days of the week for 30 minutes or more each time?' Participants who selected 'yes' were considered as meeting the public health guidelines for levels of physical activity. Participants were then presented with a list of 20 common barriers that potentially prevent people from engaging in physical activity and were asked to select any items that applied to them. Self-efficacy for physical activity was measured using a five-item scale (McCormack et al, 2003). Items were rated on a three-point Likert scale, from $0=$ 'not at all confident' to $2=$ 'very confident', with a higher score indicating a higher level of efficacy; the Cronbach's alpha of the scale was 0.96.

Knowledge with respect to physical activity was also measured on a five-item scale (Australian Institute of Health and Welfare, 2003). Participants were given five statements about their physical activity and health and were asked to rate them on a five-point Likert scale, from $0=$ 'strongly disagree' to $4=$ 'strongly 
agree', with a higher score indicating a better knowledge of physical activity; the Cronbach's alpha of the scale was 0.92 . Social support for physical activity was measured by a 4-item scale adapted from the RESIDE Project (Giles-Corti et al, 2007). Participants were asked to rate how often their family, partner, friends and colleagues had given them encouragement to be physically active in the previous month. Response options ranged from $0=$ 'rarely' to 4 = 'very often', with a higher score indicating a higher level of social support; the Cronbach's alpha of the scale was 0.78 .

\section{General health}

Perception of general health was measured by a single item: 'In general would you say your health is...' Response options ranged from $0=$ very poor to $5=$ excellent (DH, 2004a). In addition, participants were asked to identify how often they had seven hours of sleep a night, with choices ranging from $0=$ seldom or never to $4=$ always.

\section{Smoking}

Participants were asked whether they smoked cigarettes or a pipe at the time of study (DH, 2004a). For participants who were smoking at the time of study, their intention to quit smoking was measured on a five-point Likert scale, from 0 = ' $\mathrm{I}$ have no intention of giving up smoking' to $5=$ 'I intend to give up smoking within the next month'. Knowledge about dangers of passive smoking was assessed by a single item: 'Do you think that breathing someone else's smoke is dangerous to your health?'

\section{Diet}

The diet of participants was measured by the following questions: 'How often do you eat five servings of fruit/ vegetables a day?'; 'How often do you eat foods 
high in fat and sugar?'; 'How often do you eat lentils, peas or beans?'; and 'How often do you drink eight glasses (two litres) of water a day?' Participants were also asked to indicate whether they considered that they ate healthily at the time of the study (Bull et al, 2008). Self-efficacy for healthy eating was measured by an eight-item scale, which was adopted from the Western Australian adults study of physical activity and modified for the context of healthy diet (McCormack et al, 2003). Participants were asked to rate how important the eight items were in deciding how much fruit and vegetables they ate using a four-point Likert scale, from 0 = 'very unimportant' to $3=$ 'very important', with a higher score indicating a higher level of self-efficacy; the Cronbach's alpha of the scale was 0.95. Social support for healthy eating was measured by a four-item scale, adopted from the RESIDE Project and modified for the context of healthy eating (Giles-Corti et al, 2007). Participants were asked to rate how often their family, partner, friends and colleagues gave them encouragement to eat healthily in the past month. Response options ranged from $0=$ 'rarely' to $4=$ 'very often', with a higher score indicating a higher level of social support; the Cronbach's alpha of the scale was 0.80 .

\section{Data analysis}

Secondary analysis was conducted on a merged dataset using SPSS for Windows 16.0. Descriptive statistics were used to describe sample characteristics and outline the health behaviour and attitudes of the participants. Chi-square $\left(\mathrm{X}^{2}\right)$ tests and independent samples t-tests were conducted to compare registered and pre-registered nurses.

\section{Results}

\section{Participant characteristics}


Of the 876 participants, $62.9 \%(n=551)$ were registered nurses and $37.1 \%$ $(n=325)$ were pre-registered nurses. Age of the participants ranged from 17-67 years, with a mean age of 35 years (standard deviation (SD)=12.2). Most of the participants (91.4\%) were female.

\section{Physical activity}

As shown in Table 1, just under half of the participants (48.6\%) reported that they did not take part in physical activity or exercise on most days of the week for 30 minutes or more each time, thereby not meeting public health recommendations for levels of physical activity (DH, 2004b). Commonly reported barriers to physical activity were: 'I don't have time to be physically active' (66.7\%); 'I'm too tired' (39.5\%); 'I cannot afford it' (33.6\%); and 'I have no motivation' (29.6\%). The average score for knowledge about physical activity was relatively high, indicating that participants were generally knowledgeable about physically activity and health (mean $=2.62, \mathrm{SD}=0.52)$. However, mean scores for self-efficacy for physical activity (mean=0.89, $\mathrm{SD}=0.51$ ) and social support for physical activity (mean=1.47, $\mathrm{SD}=1.02$ ) were low, indicating that most participants did not perceive they had the ability to engage in regular physical activity, or support from friends and family to do so.

Pre-registered nurses were less likely to take part in regular physical activity than registered nurses $\left(\mathrm{X}^{2}(1)=5.44, \mathrm{P}<0.05\right)$ and this group also reported a greater number of barriers to being physically active (see Table 1). Independent samples t-tests showed that pre-registered nurses scored significantly lower in self-efficacy for physical activity $(\mathrm{t}(759.6)=-4.92, \mathrm{P}<0.001)$ than registered nurses. No significant differences were found in knowledge about physical activity or social support for physical activity. 


\section{General health}

Table 2 shows details regarding the general health of the participants. The mean score for the general perception of health of the participants was relatively low (mean=2.02, SD=1.07). The mean body mass index (BMI) of participants was $24.76(\mathrm{SD}=4.82)$. Based on the classification of the World Health Organization (2000), $26.9 \%$ of the participants were classified as overweight and $11.5 \%$ as obese. More than a third of participants (39.7\%) reported that they did not get seven hours of sleep more than half of the time. Registered nurses reported significantly higher scores in their general perception of health than preregistered nurses $(\mathrm{t}(611.4)=-11.5, \mathrm{P}<0.001)$. They were also more likely to report regularly getting seven hours of sleep per day $\left(\mathrm{X}^{2}(4)=39.47, \mathrm{P}<0.001\right)$. BMI levels were significantly lower among pre-registered nurses compared with registered nurses $(\mathrm{t}(662.8)=-4.12, \mathrm{P}<0.001)$, although pre-registered nurses were significantly younger $(\mathrm{t}(850)=-25.2, \mathrm{P}<0.001)$.

\section{Smoking}

Just under one-fifth (18.9\%) of the sample were current smokers. The majority (89.4\%) of participants were aware of the dangers of passive smoking.

Registered nurses were more likely to be current smokers than pre-registered nurses $\left(\mathrm{X}^{2}(2)=6.1, \mathrm{P}<0.05\right)$, and registered nurses who smoked were also less likely to have the intention of quitting smoking in the following year than preregistered nurse smokers $\left(\mathrm{X}^{2}(6)=33.9, \mathrm{P}<0.001\right)$. However, registered nurses were more likely to demonstrate knowledge about the danger of passive smoking than pre-registered nurses $\left(\mathrm{X}^{2}(3)=37.01, \mathrm{P}<0.001\right)$ (see Table 3$)$.

\section{Diet}

Nearly two-thirds (64.8\%) of participants reported that they did not consume 
five portions of fruit or vegetables per day. Just under half of the participants $(42.5 \%)$ reported that they ate foods high in fat and sugar content on a daily basis. Only one-fifth (21.8\%) of participants reported that they drank eight glasses of water a day. However, a large proportion (62.2\%) of participants felt that they were eating healthily at the time of data collection. The mean scores for social support (mean=1.54, $\mathrm{SD}=1.07$ ) and self-efficacy for healthy eating (mean $=1.60, \mathrm{SD}=0.53$ ) were relatively low, indicating that most participants did not feel they had the ability to eat healthily or support from their friends and family to do so.

Registered nurses were more likely to consume five portions of fruit or vegetables per day $\left(\mathrm{X}^{2}(3)=35.1, \mathrm{P}<0.001\right)$, and were less likely to eat foods high in fat and sugar content $\left(\mathrm{X}^{2}(3)=32.6, \mathrm{P}<0.001\right)$. They were also more likely to report eating healthily $\left(\mathrm{X}^{2}(2)=8.6, \mathrm{P}<0.05\right)$, but scored significantly lower in self efficacy for healthy eating $(\mathrm{t}(729)=3.2, \mathrm{P}<0.001)$. No significant differences were found in social support for healthy eating and frequency of drinking eight glasses of water a day (see Table 4).

\section{Discussion}

Overall, our findings indicate that a large proportion of nurses engage in unhealthy lifestyle behaviour and fail to meet the government's recommended levels for physical activity. With the exception of smoking, the health profile of student nurses was poorer than that of registered nursing staff. Pre-registered nurses were less physically active, had poorer perception of general health, were less likely to eat healthily and got less sleep than registered nurses. However, registered nurses had higher BMI and were more likely to smoke than pre- 
registered nurses. While nurses were generally aware of the need for regular physical activity, this knowledge was not always translated to their own behaviour; lack of time was cited as the main barrier to being physically active. This supports suggestions in the literature that work-related stressors, such as shift work and long working hours, may lead to a neglect of physical activity needs in the nursing profession (Blaber, 2005; Chang et al, 2005; Nursing Times, 2008), and this is worrying because low levels of physical activity have been associated with other negative health behaviour (Simoes et al, 1995; Johnson et al, 1998).

Health behaviour of pre-registered nurses is important because there is evidence to suggest that health behaviour established in younger years lays the foundations for the health behaviour of later life (Weepie and McCarthy, 2002). Alberdi-Erice et al (2007) argue that nursing education alone may be insufficient for instilling healthy habits in student nurses. Consequently, tailored healthy lifestyle programmes are needed to bring about positives changes in the health habits of this population before they enter the NHS as qualified healthcare professionals. Promoting physical activity and other health behaviour among preregistered nurses will not only allow them to be optimal role models for their patients once qualified, but may also help them to cope with the stresses of the nursing profession, as research suggests that regular exercise may be beneficial in the management of work-related stress (Van Rhenen et al, 2005). Tailored interventions may eliminate barriers to being physically active among this group and improve their self-efficacy to engage in physical activity. Self-efficacy has been shown to play a significant role in the uptake and maintenance of a regular programme of exercise (Hagger et al, 2001; Gallagher 
et al, 2006). Consequently, improving self-efficacy beliefs surrounding physical activity may help to instil positive behaviour that pre-registered nurses can maintain throughout their careers.

Consistent with findings from previous studies of qualified nurses, evidence from the current study reveals that nurses exhibit poor dietary practices (Cheung, 2003; Jinks et al, 2003; Zapka et al, 2009). Almost two-thirds of the sample did not consume enough fruit and vegetables daily, and almost half regularly ate foods that were high in fat and sugar content. Our study further shows that preregistered nurses exhibit poorer dietary habits when compared with registered nurses. One potential explanation for this could be related to the heavy study schedules and financial restraints of nursing students, which may lead to an overreliance on convenience foods (Marquis, 2005). However, several interventional studies from around the globe have shown that specific health and lifestyle interventions can be successful in improving nutritional intake among nursing students (Stark et al, 2005; Yeh et al, 2005). This again points to the need for educating pre-registration nurses about the importance of transferring their knowledge about physical activity and healthy eating to their own behaviour in order to set patterns of healthy behaviour that they can continue in their career as qualified healthcare professionals. Poor weight management practices can lead to an increased risk of obesity and ill health. Perhaps unsurprisingly, results from this study reveal that over a third of participants were overweight or obese and there was a relatively low general perception of health among the nurses. Despite demonstrating more positive health behaviour, registered nurses were found to be significantly more likely to be overweight or obese. One factor that may account for this finding is the difference in age between the two groups; 
registered nurses were on average older than pre-registered nurses, and several studies have shown evidence of a linear increase in women's BMI with age (Welon et al, 2002). The high rates of overweight and obesity observed in this study are of significance because a key focus of current UK government health policy is to combat obesity in the general population, with a particular emphasis on the NHS leading by example (DH, 2009a,b). However, reducing obesity among nursing professionals is important internationally in order to ensure that nursing staff can serve as optimum role models for their patients and are not at risk of chronic health problems (Bray, 2004). Moreover, being overweight or obese can impact negatively on work performance and productivity and has in the UK been associated with high levels of sickness absence in the NHS, which not only compromises the quality of care available to patients but also presents a huge financial burden for the NHS (Williams et al, 1998; Thompson, 2007). Improving the weight management practices of nurses and reducing their risk of obesity will thus have multi-faceted benefits and should be a key focus of health promotion initiatives globally.

One area in which pre-registered nurses demonstrated more positive health behaviour than registered nurses was smoking; registered nurses were not only more likely to be current smokers but were also less likely to have the intention of quitting compared to pre-registered nurses. One factor that may account for the higher prevalence of smoking among registered nurses could be workrelated stress. Nursing is an inherently stressful occupation and past research has shown links between levels of work-related stress and heavy smoking (Muscroft and Hicks, 1998; Piko, 1999; McVicar, 2003). For example, McKenna et al (2003) studied smoking habits in 1074 qualified nurses in Northern Ireland 
and found that although most smokers had commenced smoking before qualifying, there were reports of an increase in smoking after becoming a nurse, suggesting that nursing stress played a role in maintaining smoking habits. These findings suggest that interventions that aim to support registered nurses to develop alternative stress management strategies may be beneficial for reducing smoking rates.

Overall, however, the prevalence of smoking in this study was $18.9 \%$, which is considerably lower than results from previous studies with both pre-registered and registered nurses (Ruiz and Bayle, 2003; Hodgetts et al, 2004; Vagropoulos et al, 2006; Kumbrija et al, 2007; Sezer et al, 2007; Smith and Leggat, 2007; Kutlu, 2008). It is also slightly lower than smoking prevalence figures for the general adult population in the UK, which is reported to be around $21 \%$ for 2009 (Office for National Statistics, 2011). The lower prevalence of smoking reported in this study may be attributed to the fact there has been a general reduction in smoking among the adult population in recent years; figures suggest that around 400000 people in England have quit smoking since a ban on smoking in public places came into force (DH, 2008b). The fact that fewer student nurses smoked in this study also supports the notion of changing smoking trends in the UK (Sandford, 2008).

Our study has some limitations that should be noted when interpreting findings. The data collected for this study were cross-sectional and consequently we cannot determine causal relationships, although this does allow for an insight into the current health behaviour of nurses. The study relies on self-reported data, and there is always risk that some respondents may under-report or overreport certain health behaviour in order to present a more favourable image of 
themselves. Nevertheless, the survey was anonymous and a large proportion of participants self-reported engaging in negative health behaviour.

\section{Conclusion}

With current government recognition of the importance of the health and wellbeing of NHS staff, this study provides a useful insight into the health behaviour of registered and pre-registered nurses. This study can therefore serve as an important indicator of where education and supportive services may need to be targeted. Overall, a large proportion of the nurses in this study are not engaging in the positive health behaviour that they are increasingly expected to advocate to their patients. This is particularly concerning as the health behaviour of preregistration nurses was poor and these individuals will join the NHS at a time when workplace sickness absences are at an all-time high, and nurses are increasingly being recognized as role models for health behaviour of the public. This not only has implications for their role as future health promoters, but may also impact on individual health and well-being, and the quality of care the NHS is able to provide to its patients. Improving the health and lifestyle behaviour of nursing staff, especially concerning weight management practices such as healthy eating and regular physical activity, is therefore an important area for intervention. Targeting education and support services at improving the lifestyle behaviour of preregistered nurses may be useful for bringing about positive changes in behaviour, which can then be maintained into their career as fullyqualified nursing professionals.

\section{Key Points}

- Nursing staff play an integral role in promoting healthy lifestyle 
behaviour to patients.

- Previous research has suggested that there may be a link between nurses' health and lifestyle behaviour and their tendency to raise lifestyle issues with patients.

- A large proportion of the nurses in this study are not engaging in the positive health behaviour that they are increasingly expected to advocate to their patients.

- Overall, pre-registration nurses exhibited poorer health and lifestyle behaviour when compared with registered nurses.

- Education and support services need to be targeted at improving the lifestyle behaviour of pre-registered nurses to bring about positive changes in behaviour, which can then be maintained into their career as fully-qualified nursing professionals. 


\section{References}

Alberdi-Erice MJ, Huizi-Egilegor X, Barandiaran-Lasa M, Zupiria-Gorostidi X, Uranga-Iturrioz MJ (2007) Trends in smoking and alcohol consumption among nursing students. Enfermia Clinica 17(2): 63-70

Andrea MS, Walter V, Elena B, Alfea F, Piersante S (2001) A comparison of smoking habits, beliefs and attitudes among Tuscan student nurses in 1992 and 1999. Eur J Epidemiol 17(5): 417-21

Aristizabal C, Rodriguez SM (1998) Health habits of health professionals. Revista de Enfermeria 21(237): 15-18

Australian Institute of Health and Welfare (2003) The Active Australian Survey: AGuide and Manual for Implementation, Analysis and Reporting. AIHW, Canberra Blaber AY (2005) Exercise, who needs its? Br J Nurs 14(18): 973-5

Braithwaite D, Emery J, de Lusignan S, Sutton S (2003) Using the internet to conduct surveys of health professionals: a valid alternative? Fam Pract 20: $545-51$

Bray GA (2004) Medical consequences of obesity. J Clin Endocrinol Metab 89(6): 2583-9

Bull FC, Adams EJ, Hooper PL, Jones CA (2008) Well@Work: Promoting Active and Healthy Workplaces. Final Evaluation Report, School of Sport and Exercise Sciences, Loughborough University

Chalmers K, Seguire M, Brown J (2002) Tobacco use and baccalaureate nursing students: a study of their attitudes, beliefs and personal behaviours. J Adv Nurs 40(1): $17-24$

Chang E, Hancock KM, Johnson A, Daly J, Jackson D (2005) Role stress in nurses: review of related factors and strategies for moving forward. Nurs 
Health Sci 7(1): 57-65

Cheung ST (2003) The effects of chocolates given by patients on the well-being of nurses and their support staff. Nutr Health 17(1): 65-9

Connolly MA, Gulanick M, Keough V, Holm K (1997) Health practices of critical care nurses: are these nurses good role models for patients? Am J Crit Care 16(4): 261-6

Department of Health (2004a) Choosing Health: Making Healthy Choices Easier. The Stationary Office, London Department of Health (2004b) At Least Five a Week: Evidence on the Impact of Physical Activity and its Relationship to Health. A report from the Chief Medical Officer, The Stationary Officer, London Department of Health (2008a) Healthy Weight, Healthy Lives: A Cross Government Strategy for England. The Stationary Office, London Department of Health (2008b) Smoke-free England: One Year On. The Stationary Office, London

Department of Health (2009a) NHS Health and Well-being Review. Interim Report. The Stationary Office, London Department of Health (2009b) Healthy Weight, Healthy Lives: One Year On. The Stationary Office, London

Gallagher KI, Jakicic JM, Napolitan MA, Marcus BH (2006) Psychosocial factors related to physical activity and weight loss in overweight women. Med Sci Sports Exerc 38(5): 971-80

Giles-Corti B, Knuiman M, Pikora TJ et al (2007) Can the impact on health of a government policy designed to create more liveable neighbourhoods be evaluated? An overview of the RESIDential Environment Project. NSW 
Public Health Bull 18(11-12): 238-42

Hagger MS, Chatzisarantis N, Biddle SJH (2001) The influence of self-efficacy and past behaviour on the physical activity intentions of young people. J Sports Sci 19(9): 711-25

Hicks M, McDermott LL, Rouhana N et al (2008) Nurses' body size and public confidence in ability to provide health education. J Nurs Schol 40(4): 349-54 Hillhouse JJ, Adler CM (1997) Investigating the stress effect patterns in hospital staff nurses: results of a cluster analysis. Soc Sci Med 45(12): 1781-8. 
Table 1. Differences in physical activity between registered and pre-registered nurses

\begin{tabular}{|c|c|c|c|c|c|}
\hline Variables & Range & Total & $\begin{array}{l}\text { Registered } \\
\text { nurses (n-551) }\end{array}$ & $\begin{array}{l}\text { Pre-registered } \\
\text { nurses (n-325) }\end{array}$ & $\begin{array}{l}\text { Difference between } \\
\text { groups }\end{array}$ \\
\hline & & mean $(S D)$ & mean $(\mathrm{SD})$ & mean $(\mathrm{SD})$ & \\
\hline Self-efficacy for physical activity & $0-2$ & $0.89(0.51)$ & $0.96(0.53)$ & $0.79(0.45)$ & $t(759.6)--4.92^{* * *}$ \\
\hline Knowledge about physical activity & $0-4$ & $2.62(0.52)$ & $2.62(0.54)$ & $2.62(0.49)$ & $t(847)-0.65$ \\
\hline Social support for physical activity & $0-4$ & $1.47(1.02)$ & $1.46(1.05)$ & $1.50(0.96)$ & $t(873)-0.04$ \\
\hline \multicolumn{6}{|c|}{ Physical activity: 'Do you take part in physical activity or exercise on most days of the week for 30 minutes or more each time?' } \\
\hline 'Yes' & & $51.4 \%$ & $54.6 \%$ & $46.0 \%$ & $\chi^{2}(1)-5.44^{*}$ \\
\hline 'No' & & $48.6 \%$ & $45.4 \%$ & $54.0 \%$ & \\
\hline \multicolumn{6}{|l|}{ Barriers to physical activity } \\
\hline 'I don't have time to be physically & & $66.7 \%$ & $63.9 \%$ & $71.5 \%$ & $\chi^{2}(1)-4.95^{*}$ \\
\hline 'I cannot afford it' & & $33.6 \%$ & $19.9 \%$ & $56.7 \%$ & $\chi^{2}(1)-121^{* * *}$ \\
\hline 'I'm too tired' & & $39.5 \%$ & $34.1 \%$ & $48.6 \%$ & $\chi^{2}(1)-17.3^{\cdots *}$ \\
\hline 'I have no motivation' & & $29.6 \%$ & $24.9 \%$ & $37.7 \%$ & $\chi^{2}(1)-15.3^{* *}$ \\
\hline 'Can't be bothered' & & $23.1 \%$ & $18.0 \%$ & $31.6 \%$ & $\chi^{2}(1)-20.1^{* \cdots}$ \\
\hline 'I need to rest and relax in my spar & & $25.5 \%$ & $21.4 \%$ & $32.5 \%$ & $\chi^{2}(1)-12.7^{\cdots}$ \\
\hline 'There is no-one to be physically a & with' & $20.3 \%$ & $16.4 \%$ & $26.8 \%$ & $\chi^{2}(1)-12.9^{* *}$ \\
\hline 'There are no suitable facilities' & & $13.7 \%$ & $8.5 \%$ & $22.6 \%$ & $\chi^{2}(1)-32.9^{* *}$ \\
\hline 'I am not the sporty type' & & $17 \%$ & $16.8 \%$ & $17.3 \%$ & $\chi^{2}(1)-0.01$ \\
\hline 'I don't enjoy it' & & $11.3 \%$ & $11.2 \%$ & $11.5 \%$ & $\chi^{2}(1)-0.00$ \\
\hline 'T've got young children to look af & & $16.1 \%$ & $19.7 \%$ & $9.9 \%$ & $\chi^{2}(1)-13.7^{* *}$ \\
\hline 'Traffic is too heavy/l don't feel sat & & $8.3 \%$ & $7.6 \%$ & $9.6 \%$ & $\chi^{2}(1)-0.87$ \\
\hline 'My health is not good enough to & ysically active' & $6.8 \%$ & $6.1 \%$ & $8.1 \%$ & $\chi^{2}(1)-0.97$ \\
\hline 'I'm active enough' & & $15.0 \%$ & $19.0 \%$ & $8.4 \%$ & $\chi^{2}(1)-17.0^{\cdots}$ \\
\hline 'Too fat/overweight' & & $6.7 \%$ & $5.7 \%$ & $8.4 \%$ & $\chi^{2}(1)-1.9$ \\
\hline 'I'm injured' & & $4.6 \%$ & $4.4 \%$ & $5.0 \%$ & $\chi^{2}(1)-1.3$ \\
\hline 'I have lost contact with family/frie & & $1.4 \%$ & $0.9 \%$ & $2.2 \%$ & $\chi^{2}(1)-1.5$ \\
\hline 'I might get injured or damage my & & $1.5 \%$ & $1.5 \%$ & $1.6 \%$ & $\chi^{2}(1)-0.00$ \\
\hline 'I am too old' & & $1.2 \%$ & $1.3 \%$ & $0.9 \%$ & $\chi^{2}(1)-0.02$ \\
\hline 'I don't think it's important' & & $0.8 \%$ & $0.7 \%$ & $0.9 \%$ & $\chi^{2}(1)-0.00$ \\
\hline
\end{tabular}


Table 2. Differences in general health between registered and pre-registered nurses

\begin{tabular}{|c|c|c|c|c|c|}
\hline Variables & Range & Total & $\begin{array}{l}\text { Registered } \\
\text { nurses (n-551) }\end{array}$ & $\begin{array}{l}\text { Pre-registered } \\
\text { nurses ( } \mathrm{n}-325)\end{array}$ & $\begin{array}{l}\text { Difference between } \\
\text { groups }\end{array}$ \\
\hline & & mean $(S D)$ & mean (SD) & mean $(\mathrm{SD})$ & \\
\hline Body mass index (BMI) & $14.49-49.84$ & $24.76(4.82)$ & $25.29(5.00)$ & $23.87(4.38)$ & $t(662.8)--4.12^{* *}$ \\
\hline General perception of health & $0-5$ & $2.02(1.07)$ & $2.33(0.95)$ & $1.49(1.07)$ & $t(611.4)-11.5^{\cdots *}$ \\
\hline BMI level & & & & & $\chi^{2}(3)-22.71^{\cdots *}$ \\
\hline Underweight $(<18.5)$ & & $2.5 \%$ & $2.8 \%$ & $2.1 \%$ & \\
\hline Normal (18.6-24.9) & & $59.1 \%$ & $52.5 \%$ & $69.9 \%$ & \\
\hline Overweight (25-29.9) & & $26.9 \%$ & $31.8 \%$ & $18.9 \%$ & \\
\hline Obese $(>30)$ & & $11.5 \%$ & $12.9 \%$ & $9.1 \%$ & \\
\hline Frequency of getting 7 hours of sleep & & & & & $\chi^{2}(4)-39.47^{* * *}$ \\
\hline 'Always' & & $15.1 \%$ & $19.2 \%$ & $8.0 \%$ & \\
\hline 'Most of the time' & & $44.6 \%$ & $40.5 \%$ & $51.7 \%$ & \\
\hline 'Less than half the time' & & $26.8 \%$ & $25.0 \%$ & $29.8 \%$ & \\
\hline 'Seldom or never' & & $12.9 \%$ & $15.2 \%$ & $8.9 \%$ & \\
\hline
\end{tabular}


Table 3. Smoking behaviour in registered and pre-registered nurses

\begin{tabular}{|c|c|c|c|c|}
\hline Variables & Total & $\begin{array}{l}\text { Registered } \\
\text { nurses (n-551) }\end{array}$ & $\begin{array}{l}\text { Pre-registered } \\
\text { nurses (n-325) }\end{array}$ & $\begin{array}{l}\text { Difference between } \\
\text { groups }\end{array}$ \\
\hline Currently smoking & $18.9 \%$ & $19.2 \%$ & $18.5 \%$ & $\chi^{2}(2)-6.1^{*}$ \\
\hline \multicolumn{4}{|c|}{ Knowledge about risk of passive smoking: 'Is breathing someone else's smoke dangerous to health?' } & $\chi^{2}(3)-37.01 \cdots$ \\
\hline 'Yes' & $89.4 \%$ & $92.7 \%$ & $83.7 \%$ & \\
\hline 'No' & $1.4 \%$ & $1.3 \%$ & $1.5 \%$ & \\
\hline 'Don't know' & $2.1 \%$ & $0.9 \%$ & $2.7 \%$ & \\
\hline Variables & Total & $\begin{array}{l}\text { Registered } \\
\text { nurses (n-106) }\end{array}$ & $\begin{array}{l}\text { Pre-registered } \\
\text { nurses }(n-60)\end{array}$ & $\begin{array}{l}\text { Difference between } \\
\text { groups }\end{array}$ \\
\hline \multicolumn{4}{|l|}{ Intention to quit for those who are smoking } & $\chi^{2}(6)-33.9^{\cdots}$ \\
\hline 'Glving up in next month' & $12.7 \%$ & $14.1 \%$ & $10.0 \%$ & \\
\hline 'Giving up in next 6 months' & $21.7 \%$ & $15.0 \%$ & $33.3 \%$ & \\
\hline 'Giving up in next 1 year' & $13.3 \%$ & $7.6 \%$ & $23.3 \%$ & \\
\hline 'Intend to give up but not in next 1 year' & $6.6 \%$ & $0.9 \%$ & $16.7 \%$ & \\
\hline 'No intention of giving up' & $10.2 \%$ & $7.6 \%$ & $15.0 \%$ & \\
\hline
\end{tabular}


Table 4. Differences in diet between registered and pre-registered nurses

\begin{tabular}{|c|c|c|c|c|c|}
\hline Variables & Range & Total & $\begin{array}{l}\text { Registered } \\
\text { nurses (n-551) }\end{array}$ & $\begin{array}{l}\text { Pre-registered } \\
\text { nurses (n-325) }\end{array}$ & $\begin{array}{l}\text { Difference between } \\
\text { groups }\end{array}$ \\
\hline \multicolumn{5}{|c|}{ Do you eat five servings of fruit/vegetables a day? } & \multirow[t]{4}{*}{$\chi^{2}(3)-35.1 \cdots$} \\
\hline 'Rarely' & & $13.7 \%$ & $10.3 \%$ & $19.4 \%$ & \\
\hline 'Sometimes' & & $51.1 \%$ & $47.7 \%$ & $56.9 \%$ & \\
\hline 'Every day' & & $33.9 \%$ & $40.3 \%$ & $23.1 \%$ & \\
\hline \multicolumn{3}{|c|}{ Do you eat foods high in fat and sugar? } & & & \multirow[t]{4}{*}{$\chi^{2}(3)-32.6 \cdots$} \\
\hline 'A few times a week' & & $55.5 \%$ & $61.3 \%$ & $45.5 \%$ & \\
\hline 'Once a day' & & $33.6 \%$ & $30.7 \%$ & $38.7 \%$ & \\
\hline 'Two to three times a day' & & $8.9 \%$ & $5.6 \%$ & $14.6 \%$ & \\
\hline \multicolumn{3}{|l|}{ Do you eat lentils, peas or beans? } & & & \multirow[t]{4}{*}{$\chi^{2}(3)-9.7^{*}$} \\
\hline 'Less than once a week' & & $39.2 \%$ & $37.6 \%$ & $41.8 \%$ & \\
\hline 'Three times a week' & & $54.9 \%$ & $54.6 \%$ & $55.4 \%$ & \\
\hline 'Every day' & & $4.5 \%$ & $5.8 \%$ & $2.2 \%$ & \\
\hline \multicolumn{3}{|c|}{ How often do you drink eight glasses of water a day? } & & & \multirow[t]{4}{*}{$\chi^{2}(3)-5.28$} \\
\hline 'Rarely' & & $33.6 \%$ & $31.9 \%$ & $36.3 \%$ & \\
\hline 'Sometimes' & & $43.3 \%$ & $42.5 \%$ & $44.6 \%$ & \\
\hline 'Every day' & & $21.8 \%$ & $24.0 \%$ & $18.2 \%$ & \\
\hline \multicolumn{2}{|l|}{ I currently eat healthily } & & & & \multirow[t]{4}{*}{$\chi^{2}(2)-8.6^{*}$} \\
\hline 'Yes' & & $62.2 \%$ & $65.7 \%$ & $56.3 \%$ & \\
\hline \multirow[t]{2}{*}{ 'No' } & & $33.9 \%$ & $30.3 \%$ & $40.0 \%$ & \\
\hline & & mean (SD) & mean $(\mathrm{SD})$ & mean $(S D)$ & \\
\hline Self-efficacy for healthy eating & $0-3$ & $1.60(0.53)$ & $1.56(0.55)$ & $1.68(0.49)$ & $t(729)-3.2^{* *}$ \\
\hline Social support for healthy eating & $0-4$ & $1.54(1.07)$ & $1.51(1.11)$ & $1.61(0.99)$ & $t(726.8)-1.65$ \\
\hline
\end{tabular}

